\title{
Half-sister with Father as Common Parent
}

National Cancer Institute

\section{Source}

National Cancer Institute. Half-sister with Father as Common Parent. NCI Thesaurus.

Code C96657.

A female sibling who shares the genetic makeup inherited from only the biological father. 